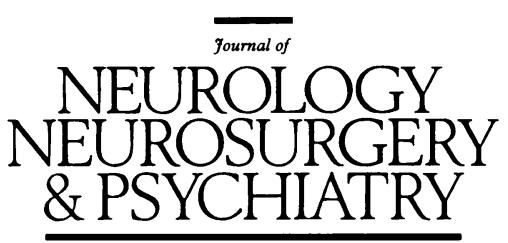

Editorial

\title{
A combined clinical and neurophysiological approach to the study of patients with tremor
}

\author{
Peter Bain
}

The accurate diagnosis of tremor is of fundamental importance to both patients and clinicians because assessment of prognosis and treatment selection depend on tremor type. Furthermore, appropriate classification is vital to the success of therapeutic trials and genetic, family and epidemiological studies. The purpose of this editorial is to review the current clinical classifications of tremor and outline the contribution of neurophysiological studies to this field.

\section{Tremor classification}

There are 2 classification systems in use. The first is based on the state of activity of a tremulous limb and the second on the aetiology of the underlying disease.

\section{A) CLASSIFICATION BY STATE OF ACTIVITY}

The following terminology was agreed upon by an ad hoc committee of the International Tremor Foundation, Tremor Investigation Group (TRIG), for classification by state of activity. ${ }^{1}$

1) "Rest" tremor: tremor which is present when a limb is fully supported against gravity and the relevant muscles are not voluntarily activated.

2) "Action" tremor: tremor occurring during any voluntary muscle contraction which includes postural, kinetic, isometric and task specific tremors.

3) "Postural" tremor: tremor apparent during the voluntary maintenance of a particular posture which is opposed by the force of gravity.

4) "Kinetic" tremor: tremor evident during any type of movement.

5) "Intention" or "terminal" tremor: the pronounced exacerbation of kinetic tremor towards the end of a goal directed movement.

6) "Task specific" tremor: tremor which only occurs to any significant extent during the performance of highly skilled activities such as writing, playing a musical instrument or using a jeweller's screwdriver. The tasks affected are usually those which require a high degree of precision and practice and take several years to acquire.

7) "Isometric" tremor: tremor which occurs when a voluntary muscle contraction is opposed by a rigid stationary object.

\section{B) CLASSIFICATION BY AETIOLOGY}

Physiological and enhanced physiological tremor

A fine action tremor is present in everyone's limbs. The tremor becomes more pronounced during periods of muscular fatigue, fear or excitement and is the result of numerous factors including the heart beat, low pass filtering properties of striated muscle, motor neuron firing and synchronisation by spindle feedback. ${ }^{2}$ Tremor amplitude can be modulated by temperature and supraspinal influences, such as vision, and also by drugs that interact with $\beta$-receptors. ${ }^{2-4} \beta$-receptor agonists such as adrenaline and salbutamol enhance physiological tremor whilst non selective $\beta$-blockers (for example, propranolol) and $\beta$-2 antagonists are more effective at preventing this than $\beta-1$ antagonists (for example, atenolol). Consequently these actions are believed to be mediated via peripheral $\beta-2$ receptors. ${ }^{2}$

\section{Parkinson's disease}

A "pill rolling" rest tremor is said to be characteristic of the disease but postural tremor is present in most cases and is symptomatic in about $60 \%$ of patients. In $10-20 \%$ of cases a rest component never in fact appears. ${ }^{56}$ Indeed, Gordon Holmes has questioned whether the hands are ever truly relaxed during Parkinsonian tremor.

Typically the tremor of Parkinson's disease is asymmetrical, at least initially, and affects an upper limb before involving the ipsilateral leg after a period of about two years. This hemi-tremulous state may remain for several years before the contralateral limbs become involved, although this is by no means always the case and occasionally this sequence is delayed or tremor first appears in the legs. The disease may also produce tremor of the lips, tongue or jaw but it rarely causes significant head or vocal tremor. ${ }^{5}$ Cogwheeling is nothing more than tremor which is palpable on passive manipulation of a limb. ${ }^{67}$ Eventually the associated signs of axial rigidity, a stooped festinant gait, poor arm swing, bradykinesia, a tendency to fall, drooling, a monotonous voice, blank facies, a reduced blink rate and difficulty initiating movements makes the diagnosis obvious. ${ }^{8}$ However, tremor is the presenting complaint in about $60-70 \%$ of cases and may remain the solitary manifestation of the condition for several years (benign tremulous Parkinson's disease). Diagnosis and classification of these patients is then difficult. The disease normally presents in the sixth or seventh decade, although it can develop at a much younger age. ${ }^{9}$ Levodopa and anti-cholinergic drugs provide the first line of treatment. ${ }^{5}$

\section{Essential tremor}

The following clinical criteria are used to make the diagnosis of definite essential tremor. ${ }^{1}$ 
a) Inclusion criteria:

1) The presence of visible and persistent postural tremor involving the hands or forearms which may or may not be accompanied by kinetic tremor. The postural upper limb tremor can be asymmetric and tremor may affect other parts of the body.

2) A prolonged duration of tremor (more than five years).

b) Exclusion criteria:

1) The presence of other abnormal neurological signs with the exception of cogwheeling (palpable tremor on passive movement of the limbs) and Froment's sign. ${ }^{10}$

2) The existence of causes of enhanced physiological tremor (for example, hyperthyroidism).

3) Concurrent or recent exposure to tremorgenic drugs or the presence of a drug withdrawal state.

4) A history of neurological trauma in the three months preceding the reported onset of tremor.

5) Clinical evidence for a psychogenic origin of tremor.

6) Tremor of sudden onset.

Essential tremor has been classified as hereditary or sporadic and has an overall population prevalence of between 0.31 and $1 \cdot 7 \% .{ }^{11} 12$ The hereditary form is inherited via a completely penetrant autosomal dominant gene. ${ }^{13}$ The age of onset is bimodally distributed with a median age of about 15 years. ${ }^{13} 14$ Disability begins in the second decade and increases with age and tremor duration. ${ }^{1315}$ The sexes are affected with equal frequency and severity. The upper limbs are affected first, usually in a symmetrical way. Tremor can then spread to affect the legs, head, facial muscles, voice and tongue. ${ }^{13}$ About $50 \%$ of affected individuals respond to alcohol whilst others (even from within the same family) do not. ${ }^{13}$ Those tremors that are suppressed by two units of alcohol invariably rebound, about 3-4 hours later, in an exacerbated form. ${ }^{13}{ }^{16}$ In controlled trials propranalol and primidone have been shown to provide a partial reduction of tremor amplitude but disability remains and patients are often troubled by side effects. ${ }^{17} 18$ The weight of current evidence is against a possible association with Parkinson's disease and, although this matter is still debated, patients with hereditary essential tremor should normally be told that they do not have an increased risk of Parkinson's disease. ${ }^{19-21}$ However, familial cases of essential tremor may be unusually sensitive to antidopaminergic drugs (for example, prochlorperazine or haloperidol)..$^{13}$

The assumption that sporadic and hereditary cases are the same entity has grown up in the literature without ever being formally studied. Task specific tremor and isolated tremors of the voice, tongue, facial muscles, head and legs have all been documented as part of the clinical spectrum of "essential tremor". ${ }^{1622-26}$ However, essential tremor may not be the appropriate label for these disorders and their true aetiologies have yet to be determined. ${ }^{13}$

The most difficult patients to classify are those with action tremors in which no associated features can be discovered. These patients are usually said to have essential tremor which is not necessarily correct. In addition, there is the practical and awkward problem of distinguishing between an enhanced physiological tremor and the early stages of a pathological one (such as, the onset of hereditary essential tremor in a young person). ${ }^{13}$ Currently there is no accepted way of making this distinction.

\section{Dystonic tremor}

Dystonic tremor occurs on action and can be broadly divided into 3 categories:

1) A postural tremor which is apparent in the out- stretched arms and is clinically indistinguishable from enhanced physiological or essential tremor. This type of tremor is often associated with spasmodic torticollis but may occur as the sole manifestation of hereditary torsion dystonia. ${ }^{27}$

2) A jerky irregular action tremor intermingled with sustained muscular spasms that can last several seconds. ${ }^{28}$ This type of tremor is often very disabling and can affect the muscles of the neck (tremulous spasmodic torticollis), face (orofacial dyskinesia), trunk and limbs.

3) A task specific movement disorder in which tremulousness and jerky spasms develop concurrently during the performance of highly skilled acts. The most common examples are tremulous writer's and typist's cramps and musician's incoordination syndrome. ${ }^{29} 30$

A combination of tremor and dystonia should prompt the clinician to investigate whether or not the dystonia is primary (idiopathic or hereditary) or secondary (symptomatic) as these are managed differently. ${ }^{31} 32$

\section{Neuropathic tremor}

Tremor is one of the manifestations of peripheral neuropathy. It is observed in some patients with acute and chronic idiopathic demyelinating, hereditary motor and sensory and IgM paraproteinaemic neuropathies and less often in the neuropathies associated with diabetes mellitus, diseases of the anterior horn cell, uraemia and porphyria. ${ }^{33-36}$ The reason for the occurrence of tremor in some patients with these conditions but not others is not understood. Characteristically an action tremor is produced which resembles essential tremor, although a "pillrolling" rest tremor, identical to that seen in Parkinson's disease, has been reported in one patient with demyelinating neuropathy. ${ }^{37}$ Symptomatic treatment with primidone, propranalol, benzodiazepines or baclofen is worth attempting but the beneficial effect of these drugs is usually rather unimpressive. Treatment should be focused on the underlying neuropathy.

\section{Midbrain ("rubral") tremor}

Midbrain lesions may produce tremor which is present at rest, worse on posture and exacerbated further by movement. ${ }^{38}$ In practice this type of tremor is most commonly seen in multiple sclerosis and brainstem vascular disease. In one patient a "rubral" tremor, which resulted from an arteriovenous malformation arising from the top of the basilar artery and draining through the mid-brain via an anomalous vein, could be suppressed by treatment with levodopa. ${ }^{39}$

Lesions dorsal to the subthalamic nucleus in the prerubral field (field $\mathrm{H}$ of Forel) can cause a contralateral tremor which is conspicuous at rest and only slightly diminished on posture and during movement (LJ Findley, personal communication).

\section{Cerebellar tremor}

The intention component of kinetic tremor is considered to be characteristic of cerebellar pathology, although it is probable that lesions of the superior cerebellar-peduncle, rather than the cerebellum itself, are responsible for this symptom. ${ }^{38}$ Various types of postural tremor have also been described including slow oscillations of the arms about the shoulders, or legs about the hips. ${ }^{4041}$ This type of tremor is referred to as titubation when it affects the head and trunk and it can be particularly striking when a patient is standing. Cerebellar tremor is normally accompanied by disorders of ocular motility, especially nystagmus and dysmetria, and often by other signs, namely incoordination, dysdiadokinesis, pendular reflexes and an unsteady gait. 


\section{Drug induced tremor}

Numerous drugs are known to produce tremor in humans. ${ }^{42}$ The two most common miscreants are probably alcohol (withdrawal or prolonged heavy ingestion) and salbutamol. Both of these drugs can cause an action tremor. Similarly insulin, by inducing hypoglycaemia, can precipitate enhanced physiological tremor in diabetic patients. An action tremor resembling enhanced physiological tremor can also be produced by a variety of substances including adrenaline, amphetamine, lithium, caffeine and steroids. ${ }^{43}$

In neurological and psychiatric practice iatrogenic tremor is frequently seen and both drug induced Parkinsonism and tremulous dyskinesias are common, as are action tremors resulting from the use of tricyclic antidepressants. ${ }^{42}$ The anti-dopaminergic drugs used in the treatment of vertigo, nausea, vomiting and schizophrenia can all incite a rest tremor indistinguishable from that seen in Parkinson's disease but more typically these drugs cause a symmetrical action tremor.

The anticonvulsants phenytoin, phenobarbitone, carbamazepine and sodium valproate can all result in an action tremor when administered in sufficiently high doses for prolonged periods. ${ }^{42}$

\section{Functional tremor}

"Functional tremor" describes tremor which is produced or exacerbated voluntarily or "subconsciously" by a patient. It is difficult to find convincing examples of this entity, especially as tremor behaviour is critically dependent on the physiological state of a person, including arousal and emotion. Furthermore, when patients with incapacitating tremors are told that their symptoms are "functional" they become quite understandably upset, which in turn exacerbates tremor magnitude. Physicians should appreciate this and be sympathetic. Some patients do appear to put on a show, but even in these instances it is worth remembering that the differentiation of a "functional" tremor from an "organic" one is inevitably dependent upon circumstantial evidence, as the hypothesis that a particular tremor does not have a pathological basis cannot be proven.

\section{The pathology of tremor}

Standard neuropathological techniques have failed to demonstrate any consistent physical or biochemical changes in brains obtained from patients in whom essential tremor had been present. ${ }^{44}$ In primary dystonia no consistent structural abnormality has been discovered, 4546 although some dysfunction in the biochemistry of the basal ganglia or brainstem is suspected. ${ }^{47} 48$ In the secondary dystonias, particularly hemidystonia, structural defects can be found in the contralateral basal ganglia but tremor is frequently absent. ${ }^{31}{ }^{32}$ In Parkinson's disease it has not as yet been possible to relate the known structural and biochemical changes to the specific symptom of tremor. ${ }^{49}$

The disease processes affecting the midbrain or cerebellum are usually too diffuse to allow accurate localisation of a potentially causal defect. For example, which of the many lesions in patients with multiple sclerosis are inciting tremor? In those rare cases in which a small focal haemorrhage or tumour within the midbrain or brainstem appears to have induced tremor the possibility that pressure effects have disabled surrounding structures cannot be discounted. Similarly infarcts are often associated with widespread cerebro-vascular disease.

Neuropathology has, until now, contributed little to tremor research.
Neurophysiological techniques used to differentiate or study tremor

A) INDIRECT METHODS Peripheral nerve conduction studies

Measurement of peripheral nerve conduction velocities might occasionally unmask an occult neuropathy in patients presenting with action tremors. Typically forearm motor nerve maximum conduction velocities are reduced to between 10 and 30 metres per second in these cases, but are normal in other types of tremor. ${ }^{35}$

\section{Simple voluntary movements}

Recording the speed of simple voluntary movements provides a useful way of detecting or quantifying bradykinesia in a tremulous limb. However, there are methodological problems caused by the fact that large movements normally produce faster maximum speeds than small ones. Because of this it is necessary to standardise the size and projection of movements by using targets. In practice targets are set at a series of distances and a graph of maximum velocity plotted against distance travelled. A further difficulty arises in patients with tremors of large amplitude because the tremor displacement is no longer a negligible proportion of the movement distance. In spite of these drawbacks it has been shown that patients with essential tremor perform simple voluntary movements at normal velocities. Those with neuropathic tremor appear to have normal maximum speeds for the sizes of the actual movements performed but in some cases are hypometric, whilst patients with Parkinsonism are usually slow (unpublished observations).

\section{B) DIRECT METHODS}

\section{Accelerometry}

Accelerometry was introduced by Agate et al in 1956 and has subsequently been widely deployed. The results are usually displayed as either power spectra, in which acceleration power $\left(\mathrm{m} / \mathrm{s}^{2}\right)^{2}$ of a tremor is plotted against frequency $(\mathrm{Hz})$, or as simple spectra (acceleration $\left(\mathrm{m} / \mathrm{s}^{2}\right)$ against frequency $(\mathrm{Hz})$ ). Modern accelerometers have a sensitivity of $0.01 \mathrm{mV} / \mathrm{cm} / \mathrm{s}^{2}$.

In 1904 Gordon Holmes suggested that the frequency of a tremor was specific to its pathophysiological origin. ${ }^{38}$ This view contains an element of truth in that specific tremor frequencies are slightly more typical of certain diseases than others. In practice, however, these frequencies overlap making the differentiation of most tremors on the basis of frequency impossible. Further complexity arises because the frequency of a tremor often varies with the site of measurement and type of action. Age is also a complicating factor, for example the $8-12 \mathrm{~Hz}$ component of physiological tremor seen in the fingers of young adults occurs at lower frequencies in children and the elderly. Similarly the frequency of essential tremor decreases with advancing age..$^{50}$

The only tremor with a diagnostic frequency is primary orthostatic tremor. This is a rare condition in which the patient's principal complaint is of unsteadiness on standing rather than walking, resulting from tremor of the lower limbs. ${ }^{51}$ In many instances the tremor is more easily palpated than seen. It has a characteristic frequency of between 14 and $18 \mathrm{~Hz}$ although episodes of period doubling have been documented. ${ }^{52}$

Accelerometry has also been used for studying the changes in tremor amplitude and frequency that occur during different tasks. The amplitude of hereditary essential tremor was found to suppress during skilled tasks, for example whilst holding a cup full of water and during a joy-stick controlled tracking test, compared with a maintained posture. The coefficient of suppression (the extent 
to which a given tremor suppresses during tasks compared to posture) is a critical factor in determining the degree of disability. ${ }^{53}$

\section{Electromyographic studies}

\section{a) Surface recordings}

The electromyographic (EMG) activity accompanying tremor may be recorded by pairs of silver/silver chloride electrodes arranged over the muscles involved in generating tremor. Bursts of EMG activity separated by relative silence occur in all types of pathological and enhanced physiological tremor but not in normal, low amplitude, physiological tremor. ${ }^{54}$ The relationship of the EMG bursts in agonist/antagonist muscle pairs has been extensively studied, but has proved to be unhelpful. Alternating and co-contracting patterns of EMG activity have been documented in most pathological types of tremor. ${ }^{5254-56}$ In addition the pattern may slip, over a period of a few minutes, from co-contracting to alternating in the same agonist/antagonist muscle pair and in some patients rhythmic activity is confined to the agonist (anti-gravity) muscles alone..$^{58}$ In IgM demyelinating neuropathic tremor the 'mode locking' of the phases of the EMG bursts in agonist and antagonist pairs is particularly lax. Furthermore, the frequency of the EMG bursts in distal muscle groups can intermittently drop by $1-3 \mathrm{~Hz}$ below that in the proximal muscles.

\section{b) Single motor unit studies}

Single motor unit discharges can be recorded by inserting concentric needle electrodes into the muscles involved in tremor. This technique can determine the firing rate of individual motor units, the synchronisation of units within one muscle and the synchrony and coherence of tremor in homologous muscle groups of the limbs.

In normal subjects a moderate tonic contraction produces motor unit discharge rates of about $10-15 \mathrm{~Hz}$. In patients with Parkinson's disease or essential tremor the motor units fire in bursts of up to $50 \mathrm{~Hz}$, which are grouped into the active period of each tremor cycle. In both essential tremor and Parkinson's disease there is another tendency for discharges from separate motor units to synchronise over a shorter time period. Single motor unit studies have shown a difference in the recruitment order of units within each tremor cycle in essential tremor and Parkinson's disease. In essential tremor the recruitment pattern is disrupted whereas in Parkinson's disease it is normal. ${ }^{54} 59$

Knowledge of the processes that compel motor unit discharges to become grouped into bursts is fundamental to understanding tremor pathophysiology. Some insight into this temporal restriction on motor unit firing has been obtained from the application of non-linear dynamics. ${ }^{60}$ In patients with essential tremor it has been shown that as tremor severity increases attractor dimension decreases (in simplified terms, as amplitude increases the number of possible alternative stable solutions towards which the system may tend becomes more limited). This suggests that essential tremor results from a reduction in the functional degrees of freedom within the involved neural pathways. ${ }^{61}$

\section{Resetting tremor}

Attempts have been made to differentiate tremors by using various stimuli to alter the phase of ongoing tremor activity relative to the tremor phase immediately before the disturbance. ${ }^{2596263}$ Initially developed as a method of determining how susceptible a tremor generator is to peripheral inputs (mechanical wrist perturbations or median nerve shocks) the technique has stumbled on methodological problems which have led to conflicting reports. The problems have been adjusting stimulus size to tremor amplitude and standardising the inertial and stiffness characteristics of the apparatus. Even when these have been addressed the technique appears to have little discriminatory power. ${ }^{64}$

\section{Stretch reflexes}

Measurement of the forearm short and long latency stretch reflexes has become a standard technique. The wrist is placed in a manipulandum and the forearm restrained. Surface EMG electrodes are placed over the wrist flexors and the EMG activity recorded during passive wrist extension. The extension torques used have varying magnitudes and are activated for about 200 milliseconds. These normally result in a biphasic EMG response in the wrist flexors consisting of an initial short latency reflex (the $\mathrm{M} 1$ component of the response) and a long latency reflex (the M2 component). The EMG records are amplified and rectified. The resultant amplitudes, latencies and durations of the $\mathrm{M} 1$ and $\mathrm{M} 2$ components are averaged and then measured for each torque.

Abnormalities in the stretch reflexes have been found in Parkinson's disease, neuropathic, dystonic and essential tremor. In Parkinson's disease enhancement of the size of long latency stretch reflex has been consistently found in rigid patients but not tremulous ones and the duration of this response is slightly prolonged. ${ }^{5465}$ In dystonia the long latency stretch reflex has been reported to be of normal amplitude and latency but prolonged in duration compared with control subjects. ${ }^{66}$ Furthermore, the stretch reflex responses "overflow" to muscles other than those influenced by movement at the joint under study. ${ }^{67}$ The forearm stretch reflexes in essential tremor are of normal size, latency and duration but afterwards rebound oscillations occur which are said to be underdamped. ${ }^{54}$ These rebound oscillations were thought to be characteristic of essential tremor but they have also been observed in other types of action tremor. In patients with IgM paraproteinaemic demyelinating neuropathic tremor, the short and long latency stretch reflexes were present but diminished in size and delayed.

\section{Reciprocal inhibition of the forearm $\mathrm{H}$-reflex}

One of the manifestations of hereditary torsion dystonia is lone postural tremor. ${ }^{276869} \mathrm{~A}$ problem arises in distinguishing these patients from those with essential tremor. One possible way of doing this is to examine the effect of radial nerve stimulation on the ipsilateral median nerve $\mathrm{H}$-reflex. In patients with dystonia there is a reduction in the depth of the presynaptic phase of inhibition compared with normal controls. ${ }^{70}$ This non-specific abnormality has not been found in patients with essential or primary writing tremor. Abnormalities in the H-reflex recovery curve have also been described in idiopathic torsion dystonia but not in essential tremor. ${ }^{71}$

\section{Positron emission tomography}

Positron emission tomography (PET) is being used in tremor research in two separate ways. The first is as a technique to measure the rate of $F^{18}$-dopa uptake by the basal ganglia. Results have shown that in Parkinson's disease the rate of $F^{18}$-dopa uptake by the putamen is diminished and usually asymmetrical, whilst in essential tremor it appears to be normal. ${ }^{72} 73$ Patients with "isolated" leg tremor tend to show striatal $F^{18}$-dopa influx constants more typical of Parkinson's disease than essential tremor. ${ }^{73}$ Second, by using $\mathrm{O}^{15}$ labelled $\mathrm{CO}_{2}$ it is possible to discover the changes in regional cerebral blood flow (rCBF) which occur during involuntary tremor 
compared with a resting state or passively induced tremor. These regional increases in CBF are believed to be the result of locally enhanced neuronal activity. Clearly, an active tremor generator or a neuronal network involved in an oscillator loop would be expected to cause focal increases in cerebral blood flow (rCBF) during tremor. Initial work on patients with essential tremor and neuropathic tremor has suggested that there is overactivity of the cerebellar circuitry whilst tremor is occurring and even during rest in both groups of patients compared with normal subjects. ${ }^{74-76}$ Whether this applies to other forms of tremor remains to be seen. Studies using $F^{18}-2$ deoxyglucose on patients with essential tremor have been reported to show medullary hypermetabolism which was thought to be indicative of over activity of the inferior olive. ${ }^{77}$ The results of future studies should be intriguing, especially if the powers of resolution of PET can be improved. In particular PET studies may help resolve a fundamental question: are all tremors the expressions of a single defective oscillator loop or generator, or do they represent lesions in different tremorgenic systems? Furthermore, if one system is responsible, do the different causes of tremor produce lesions at different loci within this system?

\section{Conclusion}

Both the aetiological and state of activity classifications are widely used, often concurrently, but they have inherent faults. The former assumes that the cause of tremor is known, whereas often no conclusive diagnosis can be made. The latter has practical drawbacks, in particular the contradiction inherent in describing a tremulous limb as "at rest" and the difficulty of differentiating the intention component of tremor from the other kinetic and postural components. ${ }^{78}$

In a very limited number of tremulous patients neurophysiological techniques are of some help in making a firm diagnosis, not least because they offer an opportunity for more prolonged periods of observation than is generally available in clinical practice. However, the techniques themselves provide scant diagnostic power and add little to the routine management of most patients. At best these types of study uncover some of the subtler abnormalities associated with different sorts of tremor. Nevertheless, patients are invariably pleased to have had their symptoms taken seriously because tremor can be a severely incapacitating condition.

Department of Neurology,

PETER BAIN

Radcliffe Infirmary,

Woodstock Road,

Oxford OX2 6HE, UK

1 Findley LJ, Koller WJ, De Witt P, et al. Classification and definition of tremor. World Neurology 1993; (in press).

2 Marsden CD. Origins of normal and pathological tremor. In: Findley LJ and Capildeo R, eds. Movement disorders: tremor. London: Macmillan Press, 1984:37-84.

3 Arblaster LA, Elton RJ, Lakie M, Walsh EG, Wright GW. Human physiological tremor-a relationship with limb temperature. If Physiol 1990 423:71P.

4 Isokawa-Akesson M, Komisaruk BR. Tuning the power spectrum of physiological finger tremor frequency with flickering light. $\mathcal{F}$ Neurosci Res 1985;14:373-80.

5 Elble RJ, Koller WC. Tremor. Baltimore and London: Johns Hopkins University Press 1990:118-33.

6 Lance JW, Schwab RS, Peterson EA. Action tremor and the cogwheel phenomenon in Parkinson's disease. Brain 1963;86:95-110.

7 Findley LJ, Gresty MA, Halmagyi GM. Tremor, the cogwheel phenomenon and clonus in Parkinson's disease. $\mathcal{F}$ Neurol Neurosurg Psychiatry 1981;44:534-46.

8 Hoehn MM, Yahr MD. Parkinsonism: onset, progression and mortality Neurology 1967;17:427-42.

9 Quinn N, Critchley P, Marsden CD. Young onset Parkinson's disease. Movement Disorders 1987;2:73-91.

10 Froment J, Gardere H. La rigidité, et la rue dentée Parkinsonione s'effacent an repos. Revue Neurologique 1926;1:52-3.
11 Rajput AH, Offord KP, Beard CM, Kurland LT. Essential tremor in Rochester, Minnesota: a 45 year study. $\mathcal{f}$ Neurol Neurosurg Psychiatry 1984;47:466-70.

12 Larsson T, Sjogren T. Essential tremor: a clinical and genetic population study. Acta Psychiat et Scandinavica 1960;36:1-176.

13 Bain PG, Findley LJ, Marsden CD. A study of hereditary essential tremor. Neurology 1993;43(4)Suppl 2:180

14 Gerstenbrand F, Klingler D, Pfeiffer B. Der essentielle tremor, phenomenologie und epidemiologie. Nervenarzt 1982;43:46-53.

15 Koller WC, Biary N, Cone S. Disability in essential tremor: effects of treatment. Neurology 1986;36:1001-4.

16 Critchley M. Observations on essential (heredofamilial) tremor. Brain 1949;72:113-39.

17 Findley LJ. The pharmacology of essential tremor. In: Marsden CD, Fahn S, eds. Movement disorders 2. London: Butterworth, 1987:438-58.

18 O'Brien MD, Upton AR, Toseland PA. Benign familial tremor treated with primidone. BMF 1981;282:178-80.

19 Cleeves L, Findley LJ, Koller WC. Lack of association between essential tremor and Parkinson's disease. Ann Neurol 1988;24:23-6.

20 Roy M, Boyer L, Barbeau A. A prospective study of 50 cases of familial Parkinson's disease. Canadian fournal of Neurological Sciences 1983, 10:34-42.

21 Pahwa R, Koller WC. Is there a relationship between Parkinson's disease and essential tremor. Clin Neuropharmacol 1993;16:30-5.

22 Biary N, Koller WC. Essential tongue tremor. Movement Disorder 1987;2:25-9.

23 Massey EW, Paulsen GW. Essential vocal tremor: clinical characteristics and response to therapy. Southern Medical fournal 1985;78:316-17.

24 Critchley E. Clinical manifestations of essential tremor. $f$ Neurol Neurosurg Psychiatry 1972;35:365-72.

25 Rothwell JC, Traub MM, Marsden CD. Primary writing tremor. $\mathcal{f}$ Neurol Neurosurg Psychiatry 1979;42:1106-14.

26 Rosenbaum R, Jankovic J. Focal task specific tremor and dystonia: categorization of occupational movement disorders. Neurology 1988;38: 522-7.

27 Fletcher NA, Harding AE, Marsden CD. A genetic study of idiopathic torsion dystonia in the United Kingdom. Brain 1990;113:379-95.

28 Yanagisawa N, Goto A. Dystonia musculorum deformans. Analysis with electromyography. $\mathcal{F}$ Neurolog Sci 1971;13:39-65.

29 Sheehy M, Marsden CD. Writers cramp: a focal dystonia. Brain 1982 105:461-80.

30 Newmark J, Hochberg FH. Isolated painless manual incoordination in 57 musicians. F Neurol Neurosurg Psychiatry 1987;50:291-5.

31 Marsden CD, Quinn N. The dystonias (neurological disorders affecting 20,000 people in Britain). BMF 1990;300:139-44.

32 Fahn S, Marsden CD, Calne DB. Classification and investigation of dystonia. In: Marsden CD, Fahn S, eds. Movement Disorders 2. London: Butterworth, 1987:332-58.

33 Ridley A. The neuropathy of acute intermittent porphyria. $Q \mathcal{f} \mathrm{Med}$ 1969;38:307-33.

34 Said G, Bathien N, Cesaro P. Peripheral neuropathies and tremor. Neurology 1982;32:480-5.

35 Smith IS, Furness P, Thomas PK. Tremor in peripheral neuropathy. In: Findley LJ, Capildeo R, eds. Movement disorders: tremor. London: Macmillan Press, 1984;399-406.

36 Dalakas MC, Teravainen H, Engel WK. Tremor as a feature of chronic relapsing and dysgammaglobulinaemic polyneuropathy. Incidence and management. Arch Neurol 1984;47:711-14.

37 Mathews WB, Howell DA, Hughes RC. Relapsing corticosteroid dependent polyneuritis. F Neurol Neurosurg Psychiatry 1970;33:330-7.

38 Holmes G. On certain tremors in organic cerebral lesions. Brain 1904;27:360-75.

39 Findley LJ, Gresty MA. Suppression of "rubral" tremor with levodopa. BMf 1981;281:1043.

40 Holmes G. The symptoms of acute cerebellar injuries from gunshot wounds. Brain 1917;40:461-535.

41 Holmes G. The Croonian lectures on the clinical symptoms of cerebellar disease and their interpretation. Lancet 1922;1:1177-82.

42 Elble RJ, Koller WC. Tremor. Baltimore: Johns Hopkins University Press, 1990:134-142.

43 Findley LJ, and Gresty MA. Tremor. Br f Hosp Med 1981;26:16-32.

44 Rajput AH, Rozdilsky B, Ang L, Rajput A. Clinicopathologic observations in essential tremor: report of six cases. Neurology 1991;41:1422-4.

45 Zeman W. Pathology of torsion dystonias (dystonia musculorum deformans). Neurology 1970;20(suppl)79-88.

46 Zeman W. Dystonia: an overview. In: Eldridge R, Fahn S, eds. Dystonia, advances in neurology. New York: Raven Press, 1976;14:91-3.

47 Hornykiewitz O, Kish SJ, Becker LE, Farley I, Shannak K. Brain neurotransmitters in dystonia musculorum deformans. $N$ Engl $\mathcal{f}$ Med 1986; 315:347-53.

48 Zweig RM, Hedveen JC, Jankel WR, Casanova MF, Whitehouse PJ, Price DL. Pathology in brainstem regions of individuals with primary dystoDi. Pathology in brainstem regions of in

49 Marshall A. Pathology of tremor. In: Findley LJ, Capildeo R, eds. Movement disorders: tremor. London: Macmillan Press, 1984;95-123.

50 Marshall J. Observations on essential tremor. $\mathcal{F}$ Neurol Neurosurg Psychiatry 1962;25:122-5.

51 Pazzaglia P, Sabattini L, Lugarese E. Su di singulare disturbo della stazione evetta (osservazione de tre casi). Ric di Freniatri 1970;96: $450-9$.

52 Britton TC, Thompson PD, Van der Kamp W, Rothwell JC, Day BL Marsden CD. Primary orthostatic tremor: further observations in five cases. F Neurology 1992;239:209-17.

53 Bain PG, Mally J, Gresty MA, Findley LJ. Assessing the impact of essential tremor on upper limb function. $\mathcal{F}$ Neurol 1993 (in press).

54 Rothwell JC, Kachi T, Thompson PD, Day BL, Marsden CD. Physiological investigations of Parkinsonian rest tremor and benign disturbances 1. London: Academic Press, 1987:1-17.

55 Shahani BT, Young RR. Physiological and pharmacological aids in the differential diagnosis of tremor. $¥$ Neurol Neurosurg Psychiatry 1976;39: 772-83.

56 Deuschl G, Lucking $\mathrm{CH}$, Schenck E. Essential tremor: electrophysiological and pharmacological evidence for a subdivision. I Neurol Neurosurg Psychiatry 1987;50:1435-41. 
57 Koller WC, Busenbark K, Gray C, Hassanein RS, Dubinsky R. Classification of essential tremor. Clinical Neumpharmacology 1992;15:81-7. 58 Young RR, Hagbarth KE. Physiological tremor enhanced by manoeuvres affecting the segmental stretch reflex. I Neurol Neurosurg Psychiatry 1980;43:248-56.

59 Lee RG, Stein RB. Resetting of tremor by mechanical perturbations: a comparison of essential tremor and parkinsonian tremor. Annals of Neurology 1981;10:523-31.

60 Thompson JMT, Stewart HB. Non-linear dynamics and chaos: geometrical methods for engineers and scientists. Chichester: John Wiley, 1991.

61 Elble RJ. Analysis of tremor with methods of non-linear dynamics: attractor dimensions. Society for Neuroscience Abstracts 1989;15:604

62 Elble RJ, Higgins C, Moody CJ, 1987. Stretch reflex oscillations and essential tremor. $\mathcal{F}$ Neurol Neurosurg Psychiatry 1987;50:691-8.

63 Rack PMH, Ross HF. The role of reflexes in the resting tremor of Parkinson's disease. Brain 1986;109:115-41.

64 Britton TC, Thompson PD, Day BL, Rothwell JC, Findley LJ. "Resetting" of postural tremors at the wrist with mechanical stretches in Parkinson's disease, essential tremor and normal subjects mimicking tremor. Ann Neurol 1992;31:507-14.

65 Tatton WG, Lee RG. Evidence for abnormal long-loop reflexes in rigid parkinsonian patients. Brain Res 1975;100:671-6.

66 Tatton WG, Bedingham W, Verrier MC, Blair RDG. Characteristic alterations in responses to imposed wrist displacements in parkinsonian rigidity and dystonia musculorum deformans. Canadian $f$ Neurolog $S c i$ rigidity and dystor

67 Rothwell JC, Obeso A, Marsden CD. Pathophysiology of dystonias. In Desmedt JE, ed. Advances in neurology. New York: Raven Press. 1983; 39:851-63.

68 Bundey S, Harrison MJG, Marsden CD. A genetic study of torsion dystonia. $\mathcal{F}$ Med Genetics 1975;12:12-9.

69 Fletcher NA, Harding AE, Marsden CD. A case control study of idiopathic torsion dystonia. Movement Disorders 1991;4:304-9.

70 Nakashima K, Rothwell JC, Day BL, Thompson PD, Shannon K Marsden CD. Reciprocal inhibition between forearm muscles in patients with writer's cramp and other occupational cramps, symptopatients with writer's cramp and other occupational cramps, sympto-
matic hemidystonia and hemiparesis due to stroke. Brain 1989, matic hemidys

71 Panizza $M$, Lelli S, Nilsson J, Hallett $M$. H-reflex recovery curve and reciprocal inhibition of H-reflex in different kinds of dystonia. Neurology 1990;40:824-8.

72 Leenders KL, Salmon EP, Tyrrell PJ, et al. Brain L-(18F)-6-Fluorodopa and $(11 \mathrm{C})$-nomifensine uptake in patients with Parkinson's disease and healthy volunteers. $\mathcal{F}$ Cerebr Blood Flow and Metabolism 1989;9:S722.

73 Brooks DJ, Playford ED, Ibanez V, et al. Isolated tremor and disruption of the nigrostriatal dopaminergic system: an F18-dopa PET study. Neurology 1992;42:1554-60.

74 Colebatch JG, Findley LJ, Frackowiak RSJ, Marsden CD, Brooks DJ. Preliminary report: activation of the cerebellum in essential tremor. Lancet 1990;336:1028-30.

75 Brooks DJ, Jenkins IH, Bain PG, et al. A comparison of the abnormal pattern of cerebral activation associated with neuropathic and essential pattern of cerebral activation associated

76 Jenkins IH, Bain PG, Colebatch JG, et al. A PET study of essentia tremor: evidence for overactivity of cerebellar connections. Ann Neurol 1993 (in press)

77 Dubinsky R, Hallet M. Glucose hypermetabolism of the inferior olive in patients with essential tremor. Ann Neurol 1987;22:118.

78 Bain PG, Findley LJ, Atchison P, et al. Assessing Tremor Severity 7 Neurol Neurosurg Psychiatry 1993 (in press).

\section{Neurological stamp}

\section{Pieter Camper (1721-89)}

Camper trained as an artist and, in addition to studying medicine, was an outstanding eighteenth century anatomist. He discovered the processus vaginalis and gave detailed descriptions of the arm, pelvis and the inguinal canal. He was the first to distinguish different ethnic groups on the basis of the shape of their skull, and as a result of studying the works of painters and medieval manuscript illustrators, formulated the theory that intelligence was related to the facial angle. Camper also discovered the fibre structure of the lens.

After studying the anatomy of the foot he wrote a treatise in 1781 on the best type of footwear which made an important contribution to the mechanics of locomotion.

This stamp was issued by The Netherlands in 1940 (Stanley Gibbons 518, Scott B125).

L F HAAS

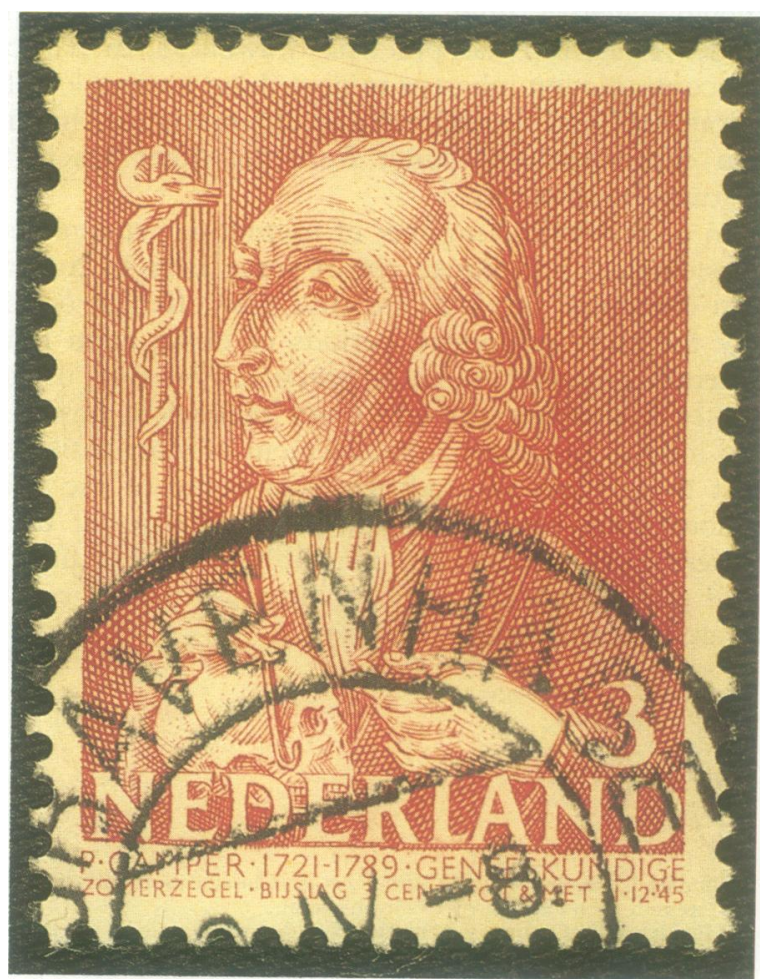

